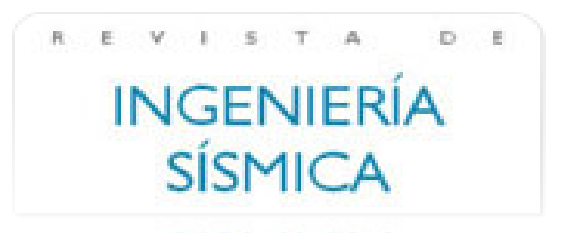

Revista de Ingeniería Sísmica

ISSN: 0185-092X

javiles@tlaloc.imta.mx

Sociedad Mexicana de Ingeniería Sísmica

México

Ferrer-Toledo, Hugo; Cárdenas-Soto, Martín; Chávez-García, Francisco J.

Site response and seismic wavefield in Toluca city, Mexico, from strong motion records

Revista de Ingeniería Sísmica, núm. 74, enero-julio, 2006, pp. 83-101

Sociedad Mexicana de Ingeniería Sísmica

Distrito Federal, México

Available in: http://www.redalyc.org/articulo.oa?id=61807403

How to cite

Complete issue

- More information about this article

Journal's homepage in redalyc.org

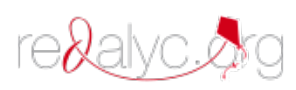

Scientific Information System Network of Scientific Journals from Latin America, the Caribbean, Spain and Portugal Non-profit academic project, developed under the open access initiative 


\title{
SITE RESPONSE AND SEISMIC WAVEFIELD IN TOLUCA CITY, MEXICO, FROM STRONG MOTION RECORDS
}

\author{
Hugo Ferrer-Toledo ${ }^{(1,2)}$, Martín Cárdenas-Soto ${ }^{(3}$, and Francisco J. Chávez-García ${ }^{(1)}$
}

\begin{abstract}
RESUMEN
Desde 1993 una red de 6 acelerógrafos opera en la ciudad de Toluca. A la fecha solo un sismo se ha registrado en las seis estaciones. Hemos analizado esos registros para medir la respuesta del sitio y analizar el campo de onda registrado. Se calcularon cocientes espectrales a partir de espectros de amplitud de Fourier, relativos a una estación de referencia y de las componentes horizontales respecto a la componente vertical registrada en cada sitio. Se compararon las trazas en diferentes bandas de periodo, se analizó la dispersión de la velocidad de grupo para cada traza y se calculó el espectro $f-k$. Los resultados muestran similitud entre el movimiento de terreno en los Valles de México y Toluca, en lo que se refiere a los efectos de trayecto. También, se muestran evidencias de arribos tardíos de energía provenientes de una dirección diferente de la epicentral. Afortunadamente para la ciudad de Toluca, las condiciones locales del suelo no amplifican el movimiento del terreno tanto como en la Ciudad de México, a pesar de los efectos de trayecto que conducen a las largas duraciones similares en periodos entre 1 y $5 \mathrm{~s}$. Se requiere un análisis más detallado, sin embargo la calidad y la cantidad de los registros disponibles no lo permite en el presente.
\end{abstract}

\begin{abstract}
Since 1993 a network of 6 accelerographs has been operating in the city of Toluca. To date, only one seismic event has been recorded by all six stations. We analyse in detail those records with the purpose of measuring site response and analyzing the recorded wavefield. We compute spectral ratios of Fourier amplitude spectra relative to a reference station and of the horizontal components relative to the vertical recorded at each site. We compare the traces in different period bands, analyse group velocity dispersion for each trace, and compute $f-k$ (frequency-wave number) spectra. Our results show, as expected, the large similarity between ground motion in the valley of Mexico and the valley of Toluca concerning path effects. We show some evidence of late arrivals of energy coming from a direction different from the epicentral one. It is fortunate for Toluca that local site effects do not amplify ground motion as much as in Mexico City, eventhough observed path effects lead to similar long durations at intermediate periods (between 1 and $5 \mathrm{sec}$ ). A more detailed analysis is needed, however the quality and quantity of the available records do not allow this at present.
\end{abstract}

\footnotetext{
Artículo recibido el 20 de septiembre de 2004 y aprobado para su publicación el 9 de marzo de 2006. Se aceptarán comentarios y/o discusiones hasta cinco meses después de su publicación.

(1) Instituto de Ingeniería, UNAM, Apdo. Postal 70-472, Coyoacán, 04510 México D.F., México. paco@pumas.iingen.unam.mx

(2) Posgrado de Geofísica, Instituto de Geofísica, UNAM. hugo.ferrer@upaep.mx

(3) DICT, Facultad de Ingeniería, UNAM. martinc@servidor.unam.mx
} 


\section{INTRODUCTION}

Subduction zone earthquakes can strongly affect central Mexico. The most obvious example is the Michoacán earthquake of 1985. The catastrophic consequences of that event in Mexico City spurred research on many different topics to explain the observed site response. The most important factor (ground motion amplification due to the very soft surficial clay layer in the lake bed zone) was quickly identified. Later studies showed, however, that other factors had contributed to the large ground motion. Among them, a very significant one is the amplification of ground on rock sites along paths perpendicular to the subduction zone, relative to paths parallel to it. This effect has been termed regional amplification.

A regional amplification of about a factor of 10 in rock sites was measured in the data of the 1985 event (Singh et al., 1988). Ordaz and Singh (1992) compiled strong motion data to elaborate attenuation laws using standard procedures and showed that sites along paths perpendicular to the Pacific coast were amplified by a factor as large as 10 in the frequency band 0.2 to $2 \mathrm{~Hz}$. They showed that this amplification appeared in the data at about $200 \mathrm{~km}$ distance from the epicenter. Cárdenas-Soto et al. (1997) constrained the geographical region where the regional amplification occurs, and presented modeling results relating the regional amplification with an irregular crustal structure between the coast and central Mexico. The analysis of strong motion data from the Mexico City accelerograph network (Chávez-García et al., 1995a; ChávezGarcía and Salazar, 2002) have shown that the more likely cause for this regional amplification is the geological discontinuity at the southern boundary of the Transmexican Volcanic Belt (TVB). This conclusion is supported by the results of numerical modeling (Furumura and Kennett, 1998), that show the large effect the 3D irregular crustal structure has on ground motion in central Mexico.

Up to now, the regional amplification has been mainly studied in terms of its consequences for ground motion in Mexico City. This was to be expected because the size and importance of this city. In addition, the density of instruments in Mexico City is unparalleled elsewhere in Mexico. However, the regional amplification affects a large area in the centre of the country, as shown by Cárdenas-Soto and Chávez-García (2003). Therefore, ground motion in other cities, like Puebla and Toluca, is also affected by the regional amplification. The lack of instrumentation, however, has hindered the analysis of ground motion in these other cities with very few exceptions (see Chávez-García et al., 1995b, for a site effect study in Puebla, for example).

Regional amplification has been identified and studied for earthquakes from the subduction zone, because reliable data are available for these events since the early 80's. However, seismic risk for cities within the TVB should also consider the occurrence of intraplate earthquakes, which can be large even if they occur with smaller frequency. These events usually take place on faults parallel to the TVB (Quinatanar et al. 2004). Some examples of intraplate events are those of January 15, 1931 (M 7.8), which caused heavy damage to the city of Oaxaca; and the earthquakes of August 28, 1973 (Mw 7.0) and October 24, 1980 (Mw 7.0), which

resulted in deaths and damages in Veracruz, Puebla, and Oaxaca. The largest historic earthquake in the TVB occurred on November, 19, 1912 (Ms 6.9) and was located $80 \mathrm{~km} \mathrm{NW}$ from Toluca 
City and $100 \mathrm{~km}$ NW of Mexico City in the Acambay Graben. This event produced considerable damages in Acambay and Texmadejé municipalities. Unfortunately, there is not enough data to investigate the way in which the regional amplification affects ground motion for earthquakes generated within the TVB.

In this paper, we present a first analysis of observed ground motion in the city of Toluca. The data we use were recorded by a strong motion network of 6 stations that has operated within this city from 1993 to date (Vera et al., 1997b). Our purpose is to analyse with as much detail as possible ground response and the seismic wavefield in Toluca. Our results show, as expected, the large similarity between ground motion in the valley of Mexico and the valley of Toluca concerning path effects. We show some evidence of late arrivals of energy coming from a direction different from the epicentral one. It is fortunate for Toluca that local site effects do not amplify ground motion as much as in Mexico City, eventhough observed path effects lead to similar long durations at intermediate periods (between 1 and $5 \mathrm{sec}$ ). A more detailed analysis is needed; however the quality and quantity of the available records do not allow this at present.

\section{DATA}

The main feature of the crustal structure in central Mexico is the Transmexican Volcanic Belt (TVB, Figure 1). Within this geological province, in the highest plain in the country at an altitude of $2650 \mathrm{~m}$ is located the city of Toluca. The geology of this region is naturally governed by volcanic rocks of Tertiary age. Similar to the valley of Mexico, the stratigraphy of Toluca basin includes alluvial sediments formed at times of subdued volcanic activity.

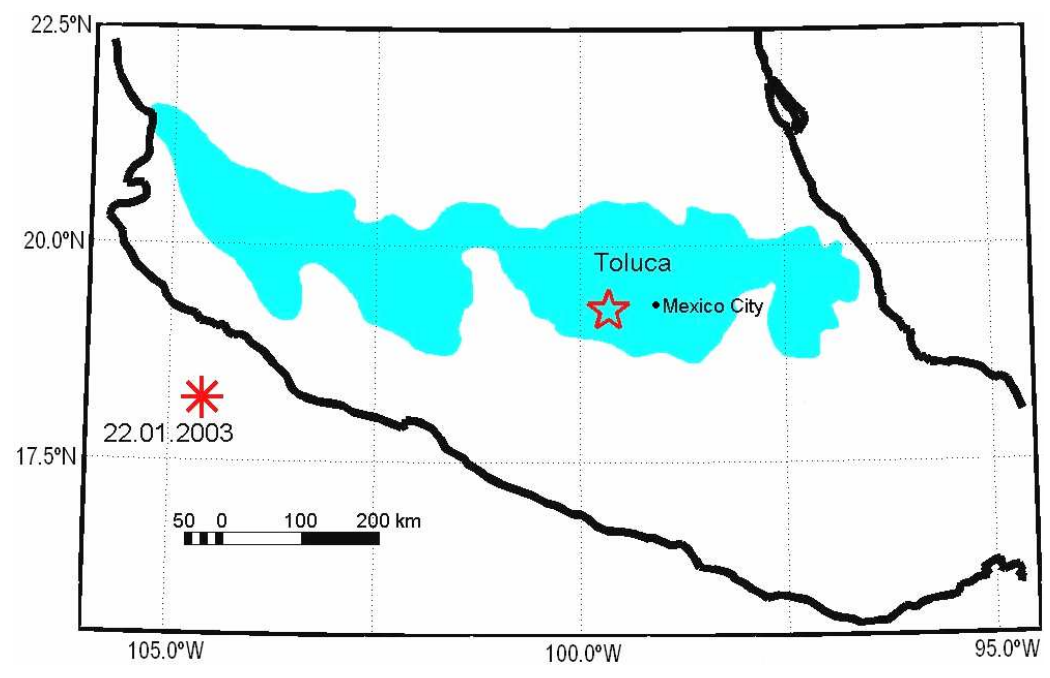

Figure 1. Location of the city of Toluca (star) within the Transmexican Volcanic Belt (shaded area), to the west of Mexico City. The asterisk shows the epicenter of the analysed event.

In 1993, the first accelerometric station was installed by Universidad Autónoma del Estado de México (UAEM) and Universidad Autónoma Metropolitana (UAM). Later, more 
instruments were added until a total of 6 autonomous stations were in operation. The instruments are Kinemetrics SSA-2 with $1 \mathrm{~g}$ full scale and damping of $70 \%$ of the critical (Vera et al., 1997b). The coordinates of the sites and site conditions are given in Table 1. Figure 2 shows the location of the stations within the city.

We have compiled the records of 7 events obtained from the Strong Motion Mexican Database (Alcántara et al., 2000). However, most of them were recorded by few stations: four events were recorded by only one station, one by two stations, and one by three stations. Only one event, located in front of Colima coast (January 22, 2003; $\mathrm{M}_{\mathrm{w}}=7.4$ ), was recorded by all six stations. Moreover, the quality of the records is low in all cases, due to the very low amplitudes of the accelerations, especially on the vertical component. For this reason, having tried to analyse all the available records, our results are mainly based on the event recorded by all six stations. This event occurred at $18.22^{\circ}$ latitude, $104.6^{\circ}$ longitude (see Figure 1), and $10 \mathrm{~km}$ depth. Its magnitude was 7.6 , and the distance from the epicenter to Toluca array was $538 \mathrm{~km}$, with a backazimuth of $258^{\circ}$ (see Figure 1).

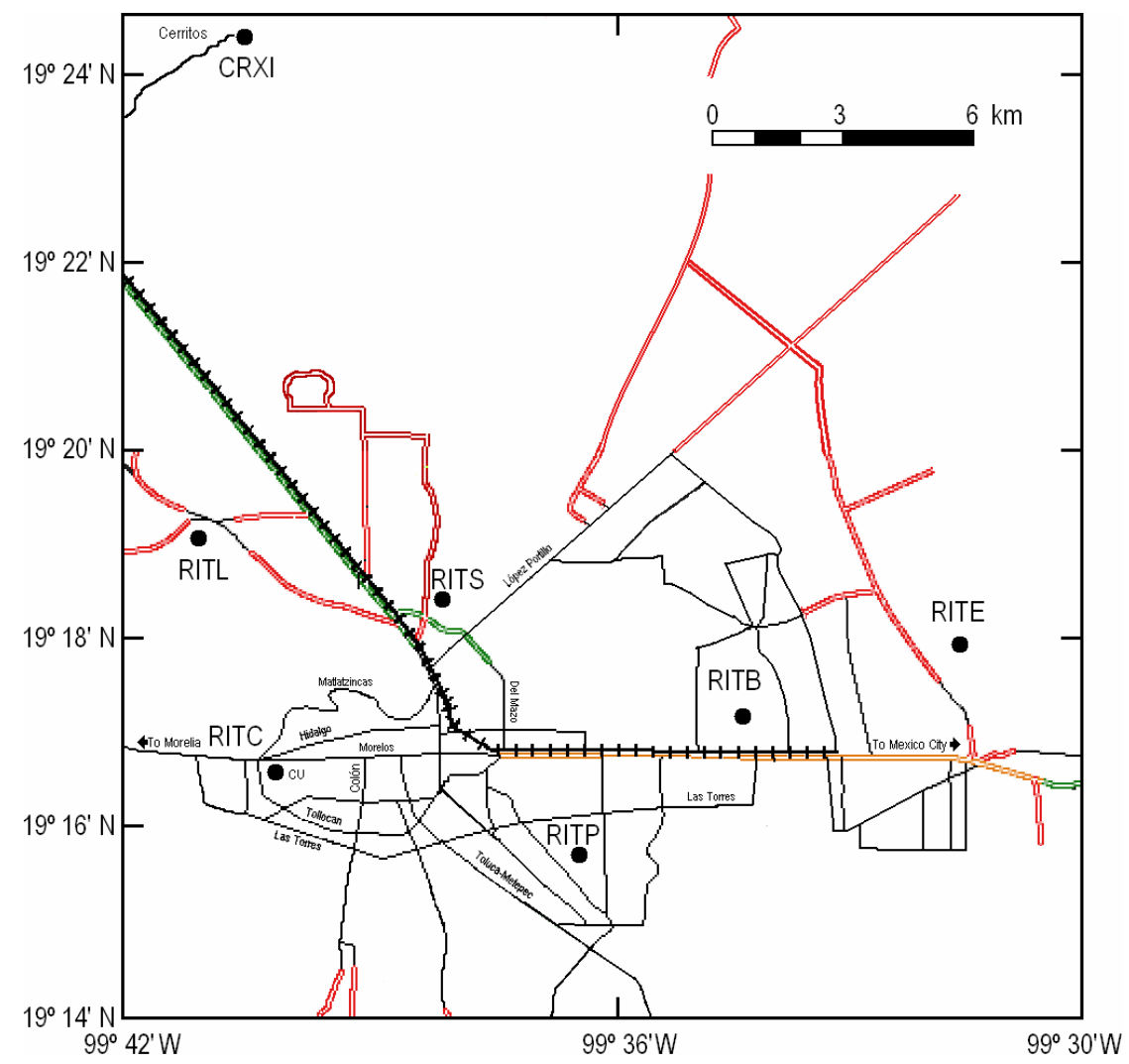

Figure 2. Location of accelerometric stations within Toluca. Station CRXI was operated as part of a temporary deployment in 1997 (see Cárdenas-Soto and Chávez-García, 2003). 
Table 1. Location of the stations and site conditions.

\begin{tabular}{|c|c|c|c|c|c|}
\hline \multirow{2}{*}{ Station } & \multicolumn{2}{|c|}{ Coordinates } & \multirow{2}{*}{$\begin{array}{l}\text { Altitude } \\
\text { (m) }\end{array}$} & \multirow{2}{*}{ Site conditions } & \multirow{2}{*}{ Location } \\
\hline & Lat. $\mathrm{N}$ & Long. W & & & \\
\hline RITB & 19.2809 & 99.5744 & 2178 & clay-sand & Cebetis 203, Metepec \\
\hline RITC & 19.2830 & 99.6764 & 2687 & rock & School of Engineering, UAEM \\
\hline RITE & 19.2985 & 99.5288 & 2179 & clay-sand & Cetis 23, Lerma \\
\hline RITL & 19.3135 & 99.6936 & 2275 & clay-sand & Language Center, UAEM \\
\hline RITP & 19.2601 & 99.6115 & 2681 & clay-sand & High school No.5, UAEM \\
\hline RITS & 19.3084 & 99.6378 & 2218 & clay-sand & School of Psychology, UAEM \\
\hline
\end{tabular}

\section{ANALYSIS}

The analysis of the records proceeded along several lines. First, we computed spectral ratios of Fourier spectra. These were computed using the reference station paradigm (e.g., Chávez-García et al., 1990) as well as using the ratio of horizontal relative to vertical components recorded at the same site (Lermo and Chávez-García, 1995). Second, we analysed in detail the observed waveforms, as a function of time and component. Third, we evaluated the group velocity of the different trains observed in the records. Finally, we computed $f-k$ spectra. The next paragraphs describe the techniques used and the results obtained.

Some of the techniques used in the analysis (dispersion and $f-k$ spectra) require absolute time for the traces, which is absent in the recorders used. We have followed the technique described by Chávez-García et al. (1995a) to assign a common time. The records were filtered between 8 and $12 \mathrm{sec}$ period. At such long periods, the dominant feature in the vertical and radial components of the records is the fundamental mode of Rayleigh waves, while the fundamental Love wave pulse is apparent in the records. Relative time among the stations was assigned, using the epicentral distance and imposing the phase velocity for that pulse computed for the model of Campillo et al. (1989). This model is a simplification of that proposed in Valdés et al. (1986), obtained from measurements between the Pacific coast of Guerrero and Oaxaca and central Mexico. This model is not adequate for our data because the structure velocity is an average between subduction zone and Mexico City. We observe that we would need to modify slightly this model, if we wanted to correctly predict arrival times of surface waves from subduction zone earthquakes to the city of Toluca. This is shown by the fact that, if we align radial components, the transversal components do not align at the expected phase velocity. However, the differences are small, and using the model of Campillo et al. (1989) to assign an absolute time to our traces is precise enough for our goals. Of course, it is desirable that in the future, as the number of records in Toluca increases, a reliable estimate of average velocities between the subduction zone and Toluca were obtained. This would also help in understanding the velocity structure within the TVB. Finally, absolute time was assigned to the traces by imposing the group velocity to the fundamental mode of Rayleigh or Love pulses recorded in the long period range. 


\section{Spectral ratios of Fourier amplitude spectra}

We have used the records for our event to study the similarities and differences of ground motion at the instrumented sites using spectral ratios. We have used two different techniques, spectral ratios relative to a reference station (usually called standard spectral ratios, or SSR) and spectral ratios of the horizontal relative to the vertical components recorded at the same site (abbreviated as HVSR, or horizontal to vertical spectral ratios). The first technique, using a reference station, was introduced by Borcherdt (1970). It relies on two hypotheses: one of the records is free from site effects (as happens if it were obtained on a flat surface without significant velocity contrasts in the underlying soil) and the distance between the two stations is small enough, relative to the epicentral distance, to accept that the incident wavefield at the two stations is exactly the same. This technique is well known, and detailed presentations of its bases and reliability have been presented in, for example, Chávez-García et al. (1990) and Field and Jacob (1995). The second technique, HVSR, inherits from the receiver function approach to the analysis of seismograms introduced by Langston (1979). It was applied to the determination of site effects using earthquake records by Lermo and Chávez-García (1993), where a thorough discussion is given. If we consider that site effects are due to the amplification caused by a single soft soil layer over a half-space, then we can characterize its seismic response using only two parameters: dominant period and maximum amplification. In the many publications in the literature on this subject, it has been usually observed that both techniques, SSR and HVSR, give the same values for dominant periods, while the amplification estimated using HVSR is usually smaller than that determined using SSR. We have used these two techniques to analyze our data. We have varied all the relevant parameters required during the analysis, such as length of time window of analysis or different smoothing filters. The results did not change significantly. The curves we show were obtained using a $100 \mathrm{sec}$ time window and smoothing using a square window of $1 / 3$ octave width.

Figure 3 shows the spectral ratios relative to station RITC, with solid lines. Solid line: average SSR for the two horizontal components relative to RITC. Dashed line: average HVSR for the two horizontal components relative to the vertical recorded at each station. CRXI: average HVSR computed for CRXI station computed by Cárdenas-Soto and Chávez-García (2003). Each curve represents the geometric average of the ratios for the two horizontal components divided by the vertical one (R/V for the radial and T/V for the transversal). Station RITL has a very similar response to RITC, although amplitudes are slightly smaller. All other stations are amplified relative to RITC. The largest amplifications occur in the band between 0.3 and $0.6 \mathrm{~Hz}$, at station RITB, and between 0.25 and $1.05 \mathrm{~Hz}$ at RITE, with peaks about a factor 4. Figure 3 allows to compare the results from SSR technique (solid lines) with those obtained using HVSR (dashed lines). The agreement between these two estimates of site amplification is variable through our stations. It is good for RITB and RITE, the two stations that show the largest amplification (a factor 4 between 0.3 and $0.8 \mathrm{~Hz}$ ). At station RITL, the agreement between SSR and HVSR is poor; while SSR indicates no amplification, HVSR suggests some amplification between 0.4 and $1 \mathrm{~Hz}$. This is due to deamplification of the vertical component at RITL as will be shown below. Station RITP shows a good agreement between the two curves, with the exception of a thin peak in the HVSR curve at $0.2 \mathrm{~Hz}$. Finally, results for RITS are similar for the two methods, but the 
amplitude of the peak at $0.6 \mathrm{~Hz}$ changes by a factor about two between the two techniques. We have superposed in Figure 3 the results obtained using HVSR at station CRXI (whose location is given in Figure 2) using records of an experiment in 1995 by Cárdenas-Soto and Chávez-García (2003). The dot-dashed line corresponds to the average HVSR for the two horizontal components and a large number of events, and is thus more reliable than the results for Toluca array. The agreement between CRXI is quite good with our stations RITB and RITE.

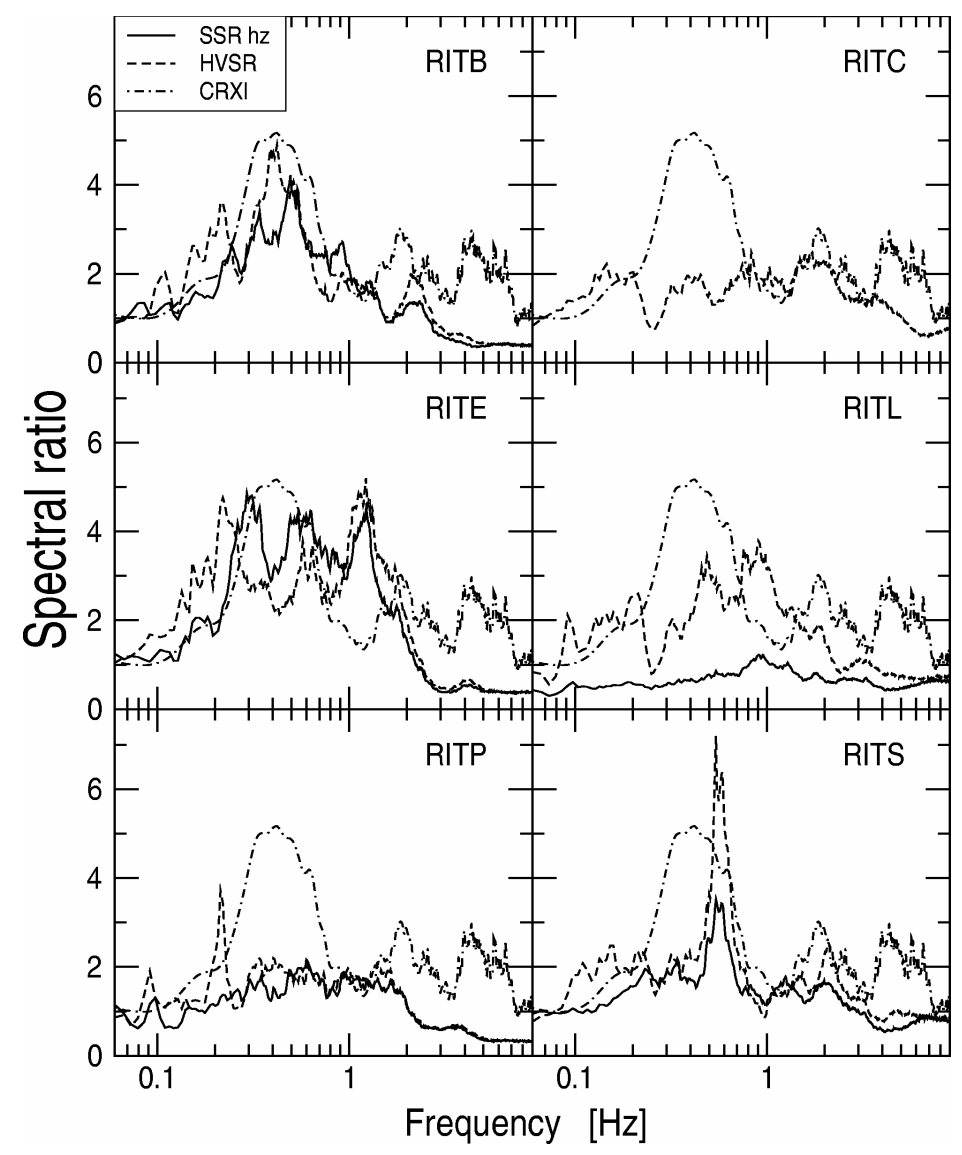

Figure 3. Solid line: SSR relative to RITC. Dashed line: average HVSR relative to the vertical recorded at each station. CRXI: average HVSR computed for CRXI station.

Figure 4 shows the results using SSR for the vertical components. Figure 4 also shows SSR for the vertical components of the Toluca array. The curve computed for CRXI was obtained using a parametric inversion of the Fourier amplitude spectra for a large number of events recorded at that station during a temporary deployment in 1997 (see Cárdenas-Soto and ChávezGarcía, 2003, where the details of the computations are given).Some amplification is observed in the band between 0.3 and $1 \mathrm{~Hz}$. The maximum amplitudes correspond again to stations RITB and RITE. We will show below that the wavefield seems to consist in a large part of Rayleigh waves. The amplification observed at stations RITB and RITE then, results from the amplification of Rayleigh waves crossing the array. It is thus natural that the vertical component should also be 
significantly amplified. SSR for the vertical component at station RITL, on the contrary, shows small amplitudes; the vertical component is deamplified at RITL relative to RITC. This explains the large amplitudes of the HVSR curve for RITL in Figure 3. Finally, Figure 4 also includes an estimate of the amplification in the vertical component at station CRXI. This estimate was derived inverting the Fourier amplitude spectra for all recorded events (Cárdenas-Soto and Chávez-García, 2003, where the details of the computations are given). The results for our stations coincide in a general way with those for CRXI, especially for station RITB, suggesting that the amplification is due to the same mechanism.

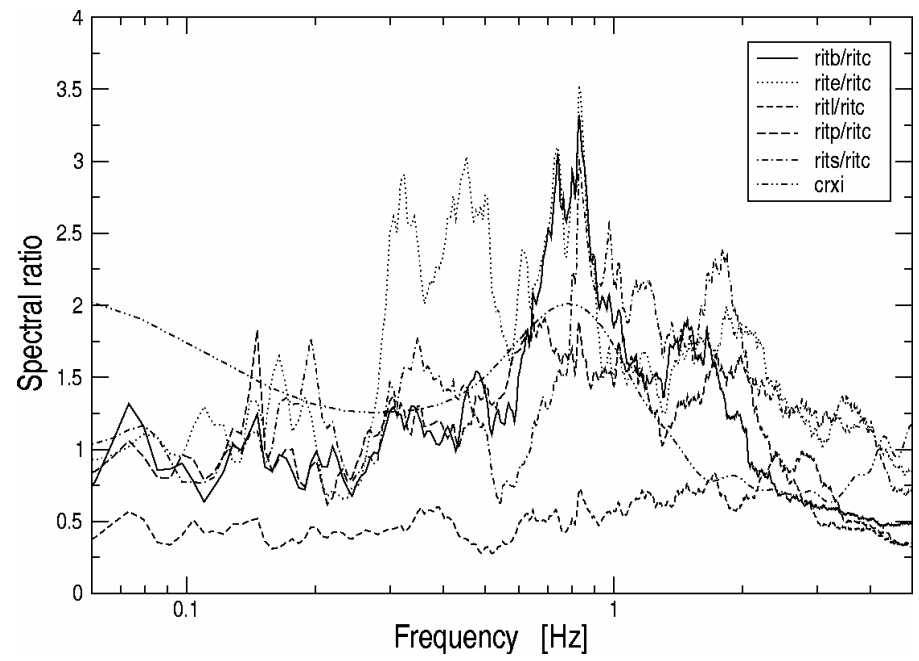

Figure 4. SSR for the vertical components of the Toluca array and CRXI station.

In spite of the differences observed in the curves of spectral ratios evaluated by SSR and HVSR, the forms of these curves exhibit a good agreement for all stations. Our results confirm the usual discrepancy observed in other studies (Field and Jacob, 1995) that show that HVSR underestimate the amplification relative obtained of SSR. Ramírez et al. (1993) and Vera et al. (1997a) studied site effects in Toluca using microtremor records and geotechnical information. According to them, local amplification occurs at frequencies between 2 and $3 \mathrm{~Hz}$. The analysis of our records does not give indications of significant amplification at those frequencies. For example, a clear site effect is observed at RITS station, where SSR and HVSR methods give a fundamental frequency of $0.55 \mathrm{~Hz}$. The simple shape shown by the transfer functions obtained for stations RITS, RITB, RITC, RITL, and RITP suggests that a simple 1D approximation may be enough to account for site effects at those sites. In Figure 5, for example, we compare the transfer functions obtained by instrumental data at station RITS (SSR and HVSR methods) with that obtained for a single layer over a half-space whose thickness to shear wave velocity ratio is 0.416 and impedance contrast is 2.75 (ratio between shear wave velocities of half-space to soil layer). Our model was computed by mean Thompson-Haskell method (Aki and Richards, 1980). We observe a good correlation between theoretical and SSR transfer function in the amplitude and the frequency of the fundamental mode. The frequency obtained by HVSR method is also obtained with 1D model, however, the amplitude requires a significant contrast of impedance. For RITE station, the spectral ratio evaluated by the two techniques is less simple (Figure 4), 
suggesting that either a more complex subsoil model or $2 \mathrm{D}$ site effects are present. The discrepancy between previous site effects studies in Toluca City and our results suggest carry out a complementary study of site effects using more earthquakes data and noise vibration measures: We cannot currently explain the differences between our results and previous estimates of site response at Toluca. However, it is generally accepted that analysis of earthquake data are more reliable than the results of microtremor measurements, especially in the case of complex site effects, as is the case in the city of Toluca.

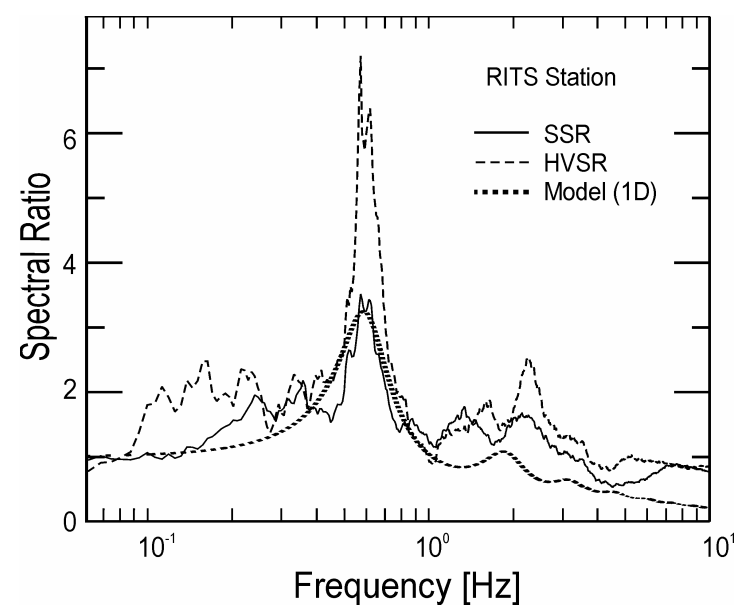

Figure 5. Comparison of transfer functions obtained by instrumental data at RITS with that obtained for a 1D model. The parameters of the model were arbitrarily chosen.

\section{Waveform analysis}

The recorded traces for the event we analyse are shown in Figure 6. All traces have been low pass filtered with a $1 \mathrm{~Hz}$ cutoff, and the stations are ordered from top to bottom with increasing epicentral distance. We observe some similarities and differences among the stations. Stations RITC and RITL, for example, have similar amplitudes in all three components. We observe that peak-to-peak amplitude increases between station RITL (top) to RITE (bottom), and this by a factor slightly larger than 3, similar as that observed in the frequency domain, for all three components of motion. Although the records for RITS and RITP seem cut by the accelerograph triggering off too soon, it is clear that the amplitudes at the end of the record at RITL are very small. This contrasts with RITB and RITE, where the final parts of the records still have significant amplitudes. Duration at RITE exceeds $150 \mathrm{sec}, 50 \%$ larger than the duration of the record at RITL.

In order to explore the nature of seismic ground motion, the records were filtered using 15 band pass filters. The central period of the Butterworth filters varied between 3.2 and $12 \mathrm{sec}$, and their passing band was a function of the central frequency. The central frequency varied according to the expression 
$f_{n}=f_{\min }(1.1)^{i-1}$

where $f_{n}$ is the central frequency of filter number $n, f_{\min }=0.06 \mathrm{~Hz}$ and $i=1,2, \ldots, 15$. The passing bandwidth of the filter was

$(1-w) f_{n}<f<(1+w) f_{n}$

where $w=0.25$. The results are shown in Figure 7 for station RITC. The topmost trace in each column is the recorded trace for each component. Below it, the result of passing it through one of the 15 band pass filters is shown. The corresponding central period of the filter is indicated to the right of the filtered traces. We observe that, for periods larger than $8 \mathrm{sec}$, the vertical and radial component show a similar pulse, that we may identify with a Rayleigh wave. The particle motion for this pulse (not shown) is elliptical retrograde. For these large periods the transversal component shows a single pulse, that arrives before the pulse observed in the radial and vertical components. We expect a larger group velocity for Love waves than for Rayleigh waves at these long periods. Thus, may identify the signal observed in the transverse component at long periods in with a Love wave. At shorter periods, between 5 and $8 \mathrm{sec}$, we observe a wavetrain at $150 \mathrm{sec}$ time that can be correlated between vertical and radial components. This pulse does not appear in the transversal component, suggesting again a Rayleigh wave. For periods smaller than $5 \mathrm{sec}$ it is no longer possible to correlate wavetrains between components. For these short periods, the records are dominated by monochromatic pulses distributed all along the records (see for example the radial component, in the time window between 210 and $220 \mathrm{sec}$ ).

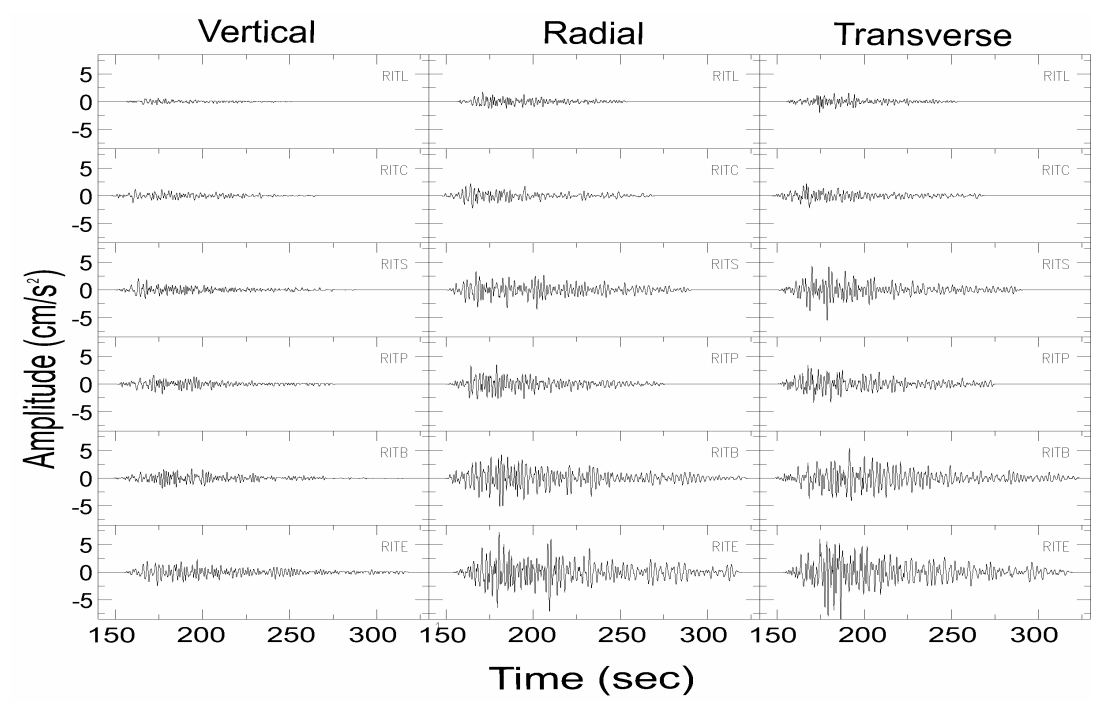

Figure 6. Acceleration records obtained at all stations, and for all three components of ground for the analysed event. The scale amplitude is common to all traces.

The other five records were analysed in the same way. For periods longer than $8 \mathrm{sec}$, we observed at all stations the same Rayleigh wave pulse identified at RITC, in the vertical and radial components. The transverse component likewise shows the Love wave pulse. Between 5 
Site Response and Seismic Wavefield In Toluca City, Mexico, From Strong Motion Records

and $8 \mathrm{sec}$ period, the Rayleigh wavetrains that we observed in the vertical and radial components of RITC station, also appear in those two components at stations RITL, RITP and RITB. In the vertical component of stations RITS and RITE the same Rayleigh pulse can be identified, however, the corresponding radial components cannot be correlated with the vertical. Being a Rayleigh wave, part of its motion must be in the radial component. However, the lack of correlation between vertical and radial components at these two stations suggests that ground motion in the radial direction includes additional contributions, with larger amplitudes. In that same period band, 5 to $8 \mathrm{sec}$, the transversal component at all stations is correlated with that at station RITC. If we go to shorter periods though, we loose all correlation among horizontal components below $5 \mathrm{sec}$ period. The vertical component, however, is still correlated among all stations between 3.8 and $5 \mathrm{sec}$ period. It is a frequent observation that the vertical component is much less affected by local conditions (for example Chávez-García and Salazar, 2002). For periods smaller than $3.8 \mathrm{sec}$ no correlation can be found among the traces.

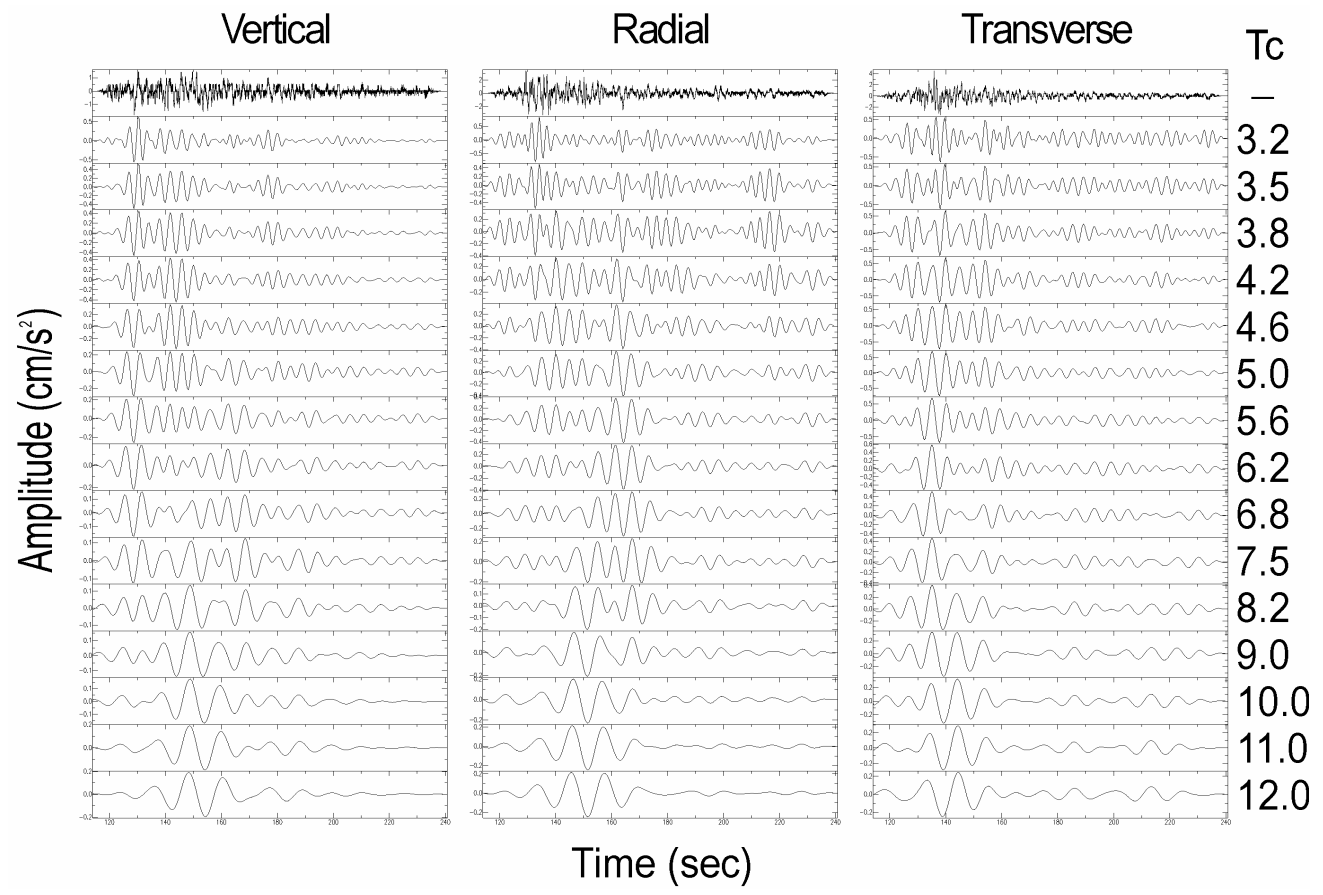

Figure 7. Records obtained at RITC and filtered by mean 15 bandpass filters. The central period is given to the right (sec). Each trace is scaled to its maximum amplitude.

We may summarize our observations as follows. For periods longer than $8 \mathrm{sec}$, surface waves travel across the array, and are similar at all stations. In the period band from 5 to $8 \mathrm{sec}$, surface waves seem to still dominate the records, however, their wavelength has decreased so much that the irregularities of the subsoil structure affects their phase and they can no longer be correlated among all the stations. As the amplitudes increase in the direction of propagation, we hypothesize that the structure becomes softer in that direction. For periods smaller than $5 \mathrm{sec}$, only vertical components are correlated, and horizontal components show several wavetrains of comparable amplitude, resulting in large duration of ground motion. 


\section{Dispersion analysis}

Another way to look at the same data is to plot the energy as a function of time and period. This can be done using the multiple filter technique (Dziewonski et al., 1969; Hermman, 1987). In this analysis the traces are bandpass filtered using a filter bank in a given period range. Then, the envelope of the resulting trace is plotted at the period of the corresponding filter. Given that the maxima of the amplitude propagate with the corresponding group velocity at each period, amplitudes are plotted against this parameter, instead of time, using the epicentral distance of the station. Finally, contours are drawn in the plane group velocity-period (U-T). Our analysis has been made between 1 and $10 \mathrm{~s}$ of period and group velocities from 2 to $4 \mathrm{~km} / \mathrm{s}$.
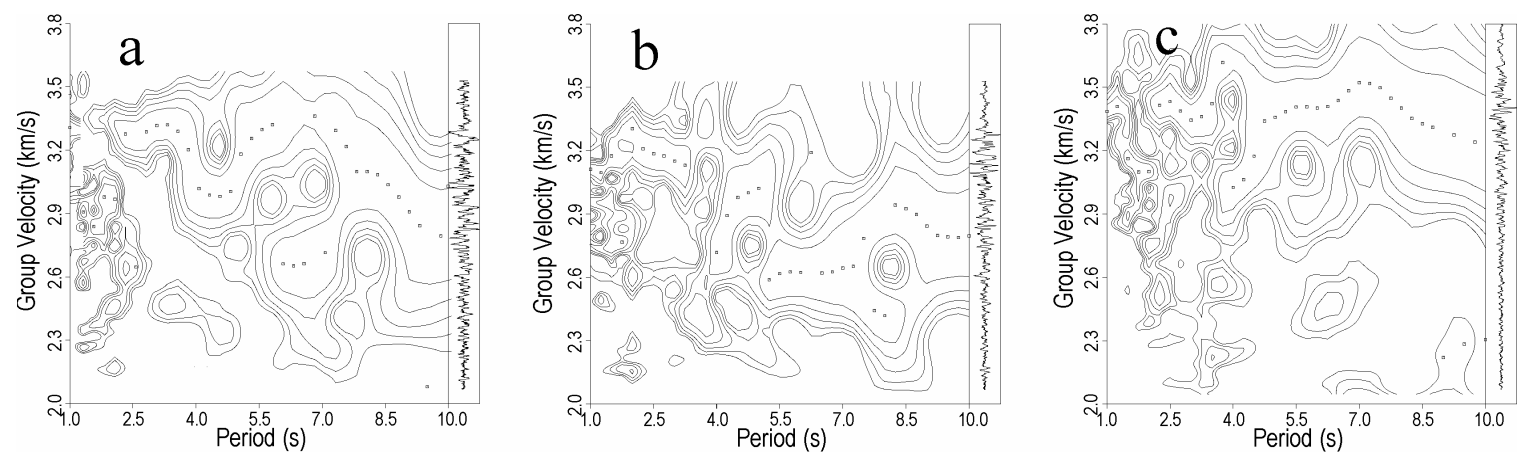

Figure 8. Contours of dispersion diagrams for the record obtained at station RITC.

a) Vertical, b) Radial, and c) Transverse components.

Figure 8 shows the results for the three components recorded at RITC station. The contours at long periods show simple forms for all three components. Contours show (Fig. 8) the energy distribution in the group velocity-period $(U-T)$ plane. To the right of each diagram, the corresponding trace is shown, plotted versus group velocity (Fig. 8) and the squares show, for each period, the location of the maximum amplitude. The vertical and radial components show a group velocity of about $2.8 \mathrm{~km} / \mathrm{s}$ in the period band from 8 to $10 \mathrm{sec}$. This corresponds to the group velocity imposed to assign absolute time to the traces. That the assigned time is correct is seen in the transverse component which shows a group velocity of about $3.2 \mathrm{~km} / \mathrm{s}$, in very good agreement with the expected group velocity for the fundamental Love wave mode. For periods smaller than $5 \mathrm{sec}$, results for both horizontal components show that there are different arrivals contributing to the signal at each period. The apparent group velocity of those arrivals is comprised between 2 and $4 \mathrm{~km} / \mathrm{s}$. The real group velocity of these arrivals is probably much smaller, as it is likely that they were generated along the path source-station (Chávez-García and Salazar, 2002). The vertical component shows some differences with the horizontals. The arrivals in the period band 2 to $5 \mathrm{sec}$ span a smaller group velocity range, and it is only for periods below $2 \mathrm{sec}$ that the arriving wavefield spans a large group velocity range (from 2 to $4 \mathrm{~km} / \mathrm{s}$ ). 


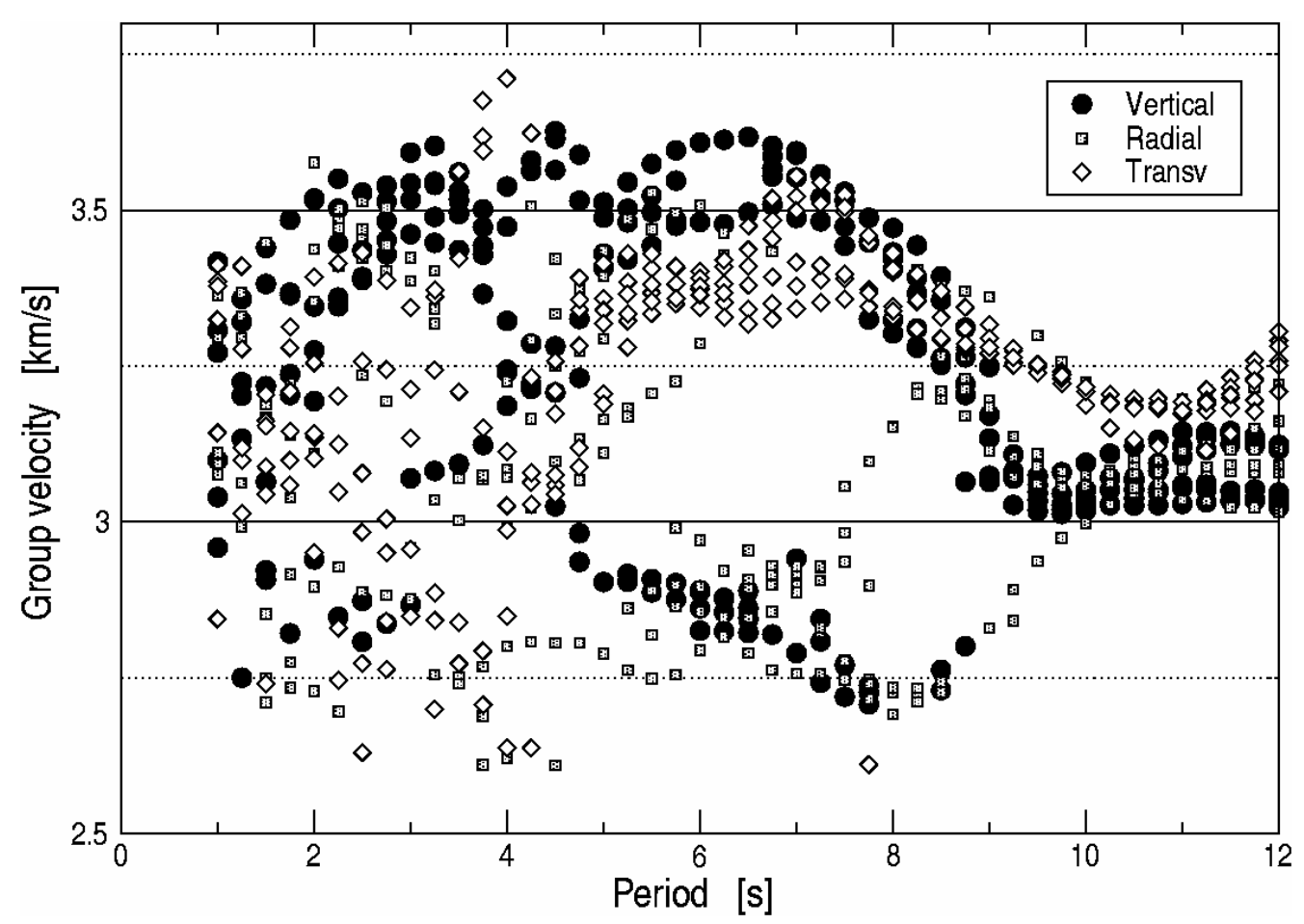

Figure 9. Coordinates of the largest peak (for each period) observed in the $U-T$ diagram for the 6 stations and the three recorded components.

The results are similar for the other 5 stations. This is shown in Figure 9. In this figure, we have plotted the coordinates of the largest amplitude peak at each period for the 6 stations and the three recorded components. The time for each record was imposed by assigning the group velocity in the transversal component at $3.2 \mathrm{~km} / \mathrm{s}$ (the expected group velocity for the fundamental mode of Love waves propagating from the source) around $10 \mathrm{~s}$ period. It is likely that this is not the correct group velocity because we observe that the scatter of the open diamonds in Figure 9 increases for periods slightly larger or smaller than $10 \mathrm{sec}$. At this period, the largest amplitudes in the vertical and radial components arrive with a group velocity between 3 and $3.1 \mathrm{~km} / \mathrm{s}$. Again, this group velocity is larger than the one predicted by the model of Campillo et al. (1989) $(2.8 \mathrm{~km} / \mathrm{s})$, which suggests significant differences in the average crustal structure between the coast of Colima and the city of Toluca. Figure 9 shows that for periods larger than about $8 \mathrm{sec}$, the dominant features in the records are the fundamental modes of Love and Rayleigh waves. At shorter periods, between 4 and $8 \mathrm{sec}$, two wave arrivals are coherent among all the stations; one with group velocities around $3.45 \mathrm{~km} / \mathrm{s}$ and one with group velocities smaller than $3 \mathrm{~km} / \mathrm{s}$. The latter appears in the vertical and radial components, suggesting a Rayleigh pulse propagating in the epicentral direction. The former has a large group velocity scatter and appears mainly in the vertical and transverse components, suggesting a diffracted Rayleigh wave pulse coming from almost $90^{\circ}$ off great circle path. The large group velocity of these pulses is too large for this period band, suggesting that they were diffracted somewhere along the path. (Group velocity is computed assuming that energy propagates from the source. If some pulse was generated by diffraction along the path, the distance travelled will be smaller, and 
so will be the corresponding group velocity.) In the period range below $5 \mathrm{sec}$, we observe a large scatter, with energy arrivals spanning a large range of group velocities. We observe no correlation between the vertical and horizontal components, suggesting that the directions of propagation do not coincide either with radial or transverse directions.

\section{$f-k$ analysis}

One of the advantages of an array is the possibility of using it as an antenna. To this end, we can use several of the different methods available (Aki and Richards, 1980). A very stable method in the presence of noise is the computation of $f-k$ (frequency-wavenumber) spectra. A $2 \mathrm{D}$ array on a flat surface allows to decompose the observed wavefield along the horizontal components of the wavenumber vector. If we perform this decomposition for the result of filtering the traces through a series of band pass filters, we obtain a series of spectra in the frequency-wavenumber domain. The maximum amplitude for each spectra gives the wavenumber coordinates of the more coherent arrivals in that frequency band for all the stations. We have used the implementation of Goldstein and Minner (1996) of Capon's (1969) high resolution method to compute $f-k$ spectra.

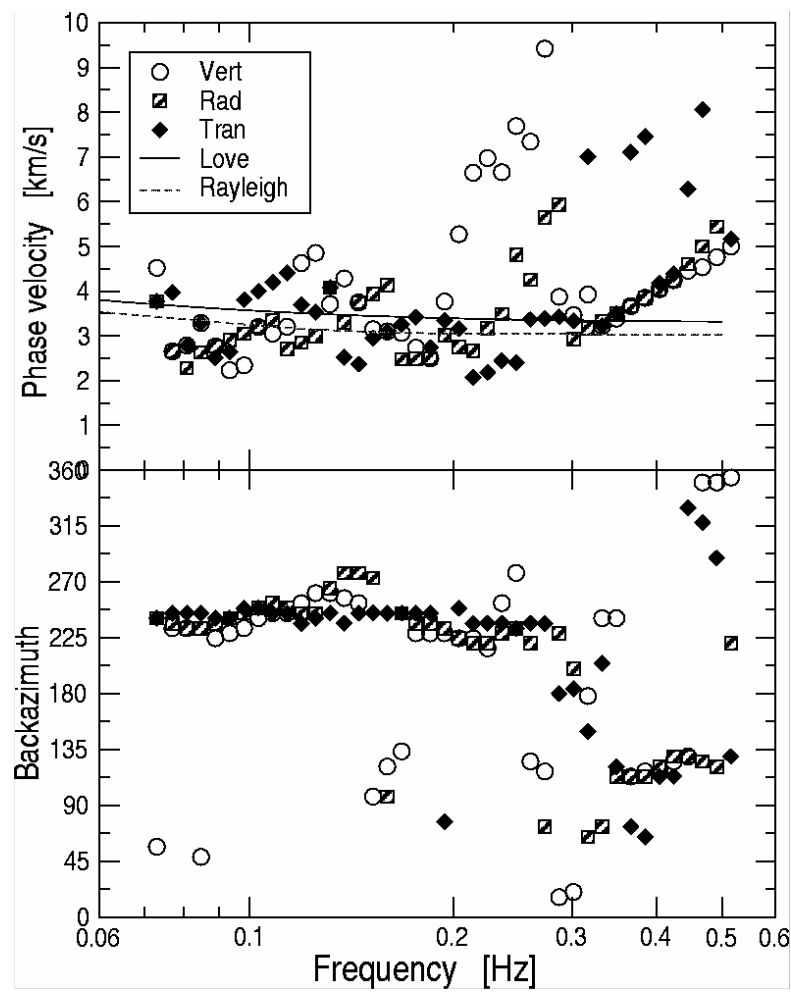

Figure 10. Results of the $f-k$ analysis. a) Phase velocity. b) Backazimuth. These values were obtained from the largest peak observed in the $f-k$ spectra computed from all 6 traces.

We tried first to use different filters and different time windows along the records to compute $f-k$ spectra (Roullé and Chávez-García, 2003). We verified that the results of the 
analysis did not depend on the particular parameters chosen for any particular computation. The width of the analysed window was a function of the central period of the filter. We made several tests imposing a phase velocity on either horizontal component. The results did not change significantly. Figure 10 shows the phase velocities and backazimuths determined from the analysis. The backazimuth shows very clearly the epicentral direction $\left(258^{\circ}\right)$ for all three components in the frequency range below $0.3 \mathrm{~Hz}$. In this frequency range, the phase velocities are scattered around the predicted phase velocities for the Love and Rayleigh fundamental modes from the model of Campillo et al. (1989). In the frequency range from $0.3 \mathrm{~Hz}$ to $0.5 \mathrm{~Hz}, \mathrm{a}$ consistent arrival is indicated for the vertical and radial components from a backazimuth of $124^{\circ}$. The corresponding phase velocity cannot be measured by the array (the symbols align on a constant wavelength line) due to aliasing problems; however, this suggests strongly that phase velocities are smaller than $2 \mathrm{~km} / \mathrm{s}$. For this reason, it is not possible to identify with certainty the geological structure that generates this arrival. However, we can speculate that it is due to the southern boundary of the TVB southern boundary, because is the most prominent geological feature to the NE of Toluca City. A similar observation was reported by Barker et al. (1996). Figure 11 shows a geological cross section under Toluca, taken from Mooser et al. (1996). We observe a layer with a thickness of about $2 \mathrm{~km}$ of vulcano-sedimentary sequences underlain by limestones. Cárdenas-Soto and Chávez-García (2003) interpreted the late arrivals observed in central Mexico as due to the diffraction at the lateral boundary of the volcanic sequences of the TVB. Our results suggest that the same mechanism is at play in Toluca.

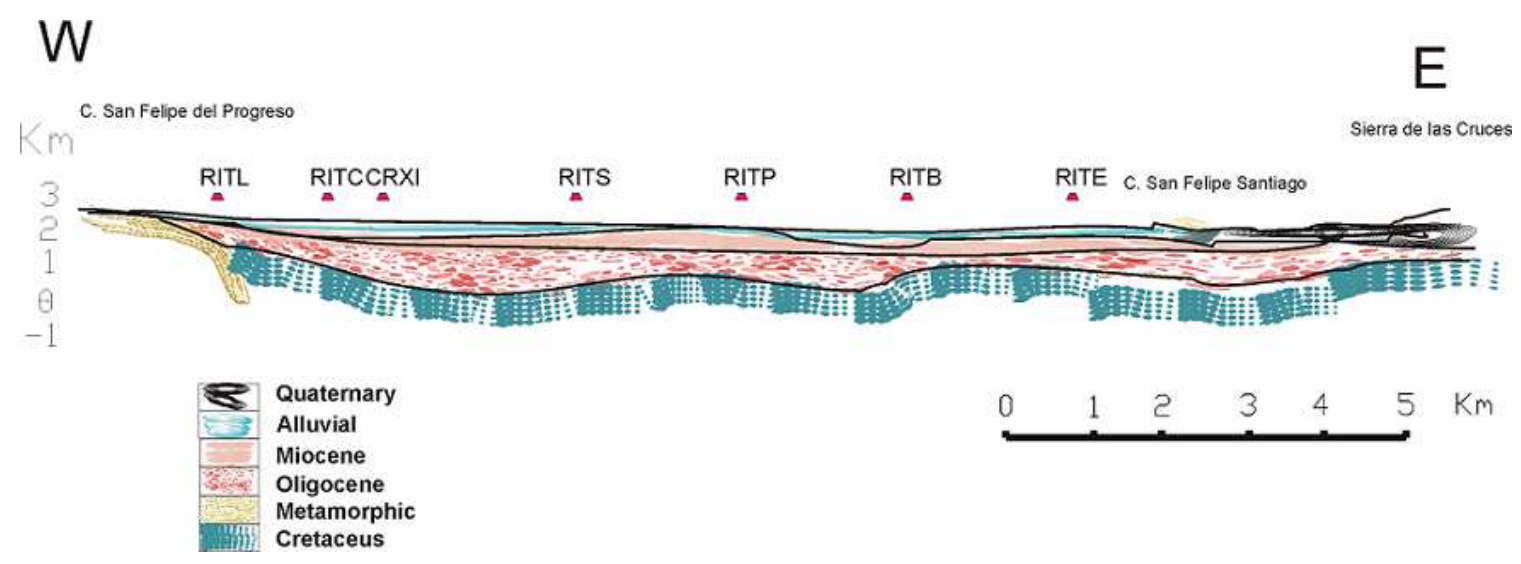

Figure 11. Geological E-W cross-section of Toluca Basin (Mooser et al., 1996). The symbols indicate the projection of the location of the strong motion stations on the section.

\section{CONCLUSIONS}

We have presented a first analysis of the characteristics of wave propagation in city of Toluca, based on the available strong motions records obtained in this city. The data come from a 6 station strong motion network installed in 1993. However, probably because of maintenance problems, only seven events have been recorded by these instruments. Moreover, only one event has been recorded by all 6 stations. We have analyzed seismic response in Toluca using spectral ratios computed for all available records, and a detailed analysis of the accelerograms obtained 
for the single event recorded by all 6 stations. We are convinced that this is the best we can do with the available data, but are aware that our results have limitations due to the lack of more earthquake records. For this reason, we regard our work only as a first contribution to the understanding of seismic ground motion in Toluca. Additional efforts should follow, especially directed towards the installation of additional seismic stations.

Our analysis explored the waveforms in the period band from 1 to $10 \mathrm{sec}$, trying to correlate ground motion among the instrumented sites. We observed that, for periods longer than $8 \mathrm{sec}$, surface waves travel across the array, and are similar at all stations. In the period band from 5 to $8 \mathrm{sec}$, surface waves seem to still dominate the records, however, their wavelength has decreased so much that the irregularities of the subsoil structure affects their phase and they can no longer be correlated among all the stations. As the amplitudes increase in the direction of propagation, we hypothesize that the structure becomes softer in that direction. For periods smaller than $5 \mathrm{sec}$, only vertical components are correlated (suggesting that horizontal motion is dominated by wavelengths smaller than the $5 \mathrm{~km}$ inter-station distance), and horizontal components show several wavetrains of comparable amplitude, resulting in large duration of ground motion.

Our analysis suggests that lateral heterogeneities in the subsoil structure significantly affect wavelengths in the order of 1 to $10 \mathrm{~km}$. The records of the analysed event show an increase of amplitude with distance from the source. This amplification occurs in the frequency band between 0.2 and $1 \mathrm{~Hz}$, similar to that reported by Ordaz and Singh (1992). There are also significant differences among the vertical components. This is obvious since our analysis suggests that ground motion consists mainly of surface waves. The irregular subsoil structure affects the propagation of these waves, whose ground motion occurs in the radial and vertical components.

A group dispersion analysis suggests that, for period larger than $8 \mathrm{sec}$, a single propagation mode is present in the records. At shorter periods, and especially for periods below 5 sec, the records include different contributions, probably arriving from different directions. This is confirmed by the $f-k$ analysis, which, although lacking resolution at shorter periods, clearly identifies a wavetrain arriving from a direction different from the epicentral. Its phase velocity cannot be measured, however, due to aliasing.

Our results show, as expected, the large similarity between ground motion in the valley of Mexico and the valley of Toluca concerning path effects. We show some evidence of late arrivals of energy coming from a direction different from the epicentral one. This is very likely due to the fact that the large scale geological structure under Toluca is very similar to that under Mexico City. It is fortunate for Toluca that local site effects do not amplify ground motion as much as in Mexico City, eventhough observed path effects lead to similar long durations at intermediate periods (between 1 and $5 \mathrm{sec}$ ).

The results presented in this paper show that site effects can and should be studied in other cities in central Mexico, and that the techniques of analysis for this are available. We point that our study indicates that seismic ground motion in the city of Toluca can be important and 
that the seismic analysis of earthquake data can be very useful to understand and predict the expected differences in ground motion between different parts of the city. However, we experience a cruel lack of data. For this reason, we would like to call attention to the urgent need of improving the seismic instrumentation in Toluca, as well as in other large cities within the TVB.

\section{ACKNOWLEDGMENTS}

We thank two anonymous reviewers, whose comments were useful to improve our manuscript. Our data were provided by RIIS-UAEM-UAM (H. Ramírez, R. Vera, S. Miranda, and M. Ramírez-Centeno). One of us (HFT) acknowledges financial support from UPAEP-SUPERAANUIES (contract 0060105-5165). Part of this research was carried out when one of us (FJCG) enjoyed a sabbatical leave from UNAM, with financial support from DGAPA, UNAM.

\section{REFERENCES}

Aki, K. and P. G. Richards (1980). Quantitative seismology, theory and methods, W.H. Freeman.

Alcántara, L., R. Quass, C. Pérez, M. Ayala, M. Macías, H. Sandoval, C. Javier, E. Mena, E. Andrade, F. González, E. Rodríguez, A. Vidal, L. Munguía, M. Luna, J. Espinosa, A. Cuellar, L. Camarillo, S. Ramos, M. Sánchez, E. Guevara, J. Flores, B. López, R. Ruiz, J. Pacheco, M. Ramírez, J. Aguilar, J. Juárez, R. Vera, A. Gama, R. Cruz, F. Hurtado, R. Martín del Campo, and F. Vera (2000). Base Mexicana de Datos de Sismos Fuertes, CD-ROM edited by Sociedad Mexicana de Ingeniería Sísmica, Vol. 2.

Barker, J. S., M. Campillo, F. J. Sánchez-Sesma, D. Jongmans, and S.K. Singh (1996). Analysis of wave propagation in the Valley of Mexico from a dense array of seismometers, Bull. Seism. Soc. Am. 86, 1667-1680.

Borcherdt, R. D. (1970). Effects of local geology on ground motion near San Francisco Bay, Bull. Seism. Soc. Am., 60, $29-61$.

Campillo, M., J.C. Gariel, K. Aki, and F. J. Sánchez-Sesma (1989). Destructive strong ground motion in Mexico City: source, path, and site effects during the great 1985 Michoacan earthquake, Bull. Seism. Soc. Am., 79, $1718-1735$.

Capon, J. (1969). High-resolution frequency-wavenumber spectrum analysis, Proc. IEEE, 57, $1408-1418$.

Chávez-García, F.J. and L. Salazar (2002). Strong motion in central Mexico: a model based on data analysis and simple modeling, Bull. Seism. Soc. Am., 92, $3087-3101$.

Chávez-García, F.J., G. Pedotti, D. Hatzfeld, and P.-Y. Bard (1990). An experimental study of site effects near Thessaloniki (Northern Greece), Bull. Seism. Soc. Am., 80, $784-806$. 
Chávez-García, F.J., Ramos-Martínez, and E. Romero-Jiménez (1995a). Surface-wave dispersion analysis in México City, Bull. Seism. Soc. Am., 85, 1116 - 1126.

Chávez-García, F. J., J. Cuenca, J. Lermo y H. Mijares (1995b). Seismic microzonation of the city of Puebla, en S. Prakash (ed.) Third Int. Conf. on Recent Advances in Geotech. Earthq. Eng. and Soil Dyn., St. Louis, Missouri, abril 2-7, II, 545 - 548.

Cárdenas-Soto, M. and F.J. Chávez-García (2003). Regional path effects on seismic motion in central Mexico, Bull. Seism. Soc. Am., 93, 973 - 985.

Cárdenas-Soto, M., F.J. Chávez-García, and A. Gusev (1997). Regional amplification of ground motion in central Mexico. Results from coda magnitude data and preliminary modeling. J. Seism., 1, $341-355$.

Dziewonsky, A., S. Bloch and M. Landisman (1969). A technique for the analysis of transient seismic signals, Bull. Seism. Soc. Am., 59, $427-444$.

Field, E. H. and Jacob K. H. (1995). A Comparison and Test of Various Site Response Estimation Techniques, Including Three that are Not Reference-Site Dependent, Bull. Seism. Soc. Am., 85, $1127-1143$.

Furumura, T. and B.L.N. Kennett (1998). On the nature of regional seismic phases-III. The influence of crustal heterogeneity on the wavefield for subduction earthquakes: the 1985 Michoacan and 1995 Copala, Guerrero, Mexico earthquakes, Geophys. J. Int, 135, 1060 - 1084.

Goldstein, P. and L. Minner (1996). SAC2000: Seismic Signal Processing and Analysis Tools For the $21^{\text {st }}$ Century, Seis. Res. Lett., 67, 39.

Herrmann, R. (1987). Computer programs in Seismology, Saint Louis University, Missouri.

Langston, C.A. (1979). Structure under Mount Rainier, Washington, inferred from teleseismic body waves, J. Geophys. Res., 84, $4749-4762$.

Lermo and Chávez-García (1993). Site effects evaluation using spectral ratios with only one station, Bull. Seism. Soc. Am., 83, 1574 - 1594.

Lermo, J.F. and F.J. Chávez-García (1995). Site effect evaluation at Mexico City: dominant period and relative amplification from strong motion and microtremor records, Soil Dyn. Earthquake Eng., 13, 413 - 423.

Mooser, F., A. Montiel, and A. Zúñiga (1996). New geologic map for Mexico, Toluca, and Puebla basins, Comisión Federal de Electricidad, México D.F., 27 pp (in Spanish). 
Ordaz, M. and S.K. Singh (1992). Source spectra and spectral attenuation of seismic waves from Mexican earthquakes, and evidence of amplification in the hill zone of Mexico City, Bull. Seism. Soc. Am., 82, $24-43$.

Quintanar L., M. Rodríguez-Gónzalez and O. Campos Enríquez (2004). A shallow crustal earthquake doublet from the Trans-Mexican volcanic belt (Central Mexico), Bull. Seism. Soc. Am., 94, $845-855$.

Ramírez H., J. L. Carmona, M. Flores, R. Vera, J. Galván, M. Ramírez, M. Ruiz-Sandoval, J. Aguilar, A. Fernández, J. Carballo, and J. Iglesias (1993). Zonificación Sísmica de la Ciudad de Toluca, Memorias X Congreso Nacional de Ingeniería Sísmica, 759 - 770.

Roullé A. and F. Chávez-García (2003). Comparación entre métodos frecuencia-número de onda y music para estudiar el campo de ondas en el valle de México, Memorias del XIV Congreso Nacional de Ingeniería Sísmica, artículo I-16, en CD-ROM.

Singh, S.K., E. Mena, and R. Castro (1988). Some aspects of the source characteristics and ground motion amplifications in and near Mexico City from acceleration data of the September, 1985, Michoacán, Mexico earthquakes, Bull. Seism. Soc. Am., 78, 451 - 477.

Valdés, C.M., W.D. Mooney, S.K. Singh, R.P. Meyer, C. Lomnitz, J.h. Luetgert, C.E. Helsey, B.T.R. Lewis, and M. Mena (1986). Crustal structure in Oaxaca, Mexico, from seismic refraction measurements, Bull. Seism. Soc. Am., 76, 547 - 563.

Vera, N., M. Ramírez; H. Ramírez H., M. Ruiz, E. Mendoza, J. García, F. Rivero, and J. Iglesias (1997a). Propuesta de Zonificación Sísmica de los municipios de Toluca, Lerma y Metepec, Estado de México, Memorias del XI Congreso Nacional de Ingeniería Sísmica, 320 - 329.

Vera, N., H. Ramírez H., and S. Miranda (1997b). Red Acelerográfica de la Ciudad de Toluca, Memorias del XI Congreso Nacional de Ingeniería Sísmica, 468 - 474. 